\title{
REVISÃO DA CLASSIFICAÇÃO DA RAÇA 3 DE Fusarium oxysporum f. sp. lycopersici *
}

\author{
Marco Antonio Noguez ** \\ HASIME TOKESHI
}

\section{RESUMO}

Os autores procuraram, face às evidências acumuladas, determinar: 1) a que raça fisiológica pertence o isolado T-18-1, descrito como raça 3 de Fusarium oxysporum f. sp. lycopersici; 2) qual o tipo de resistência que apresenta a linhagem CAST-M-Wd, usada como diferencial na determinação da raça 3 .

Para alcançar os objetivos almejados, instalaram-se 2 ensalos em casa de vegetação com controle parcial de temperatura. No ensaio I estudou-se a reação de 27 progênies de Cast-M-Wd ao isolado T-18-1, usando-se como diferenciais, a variedade Walter e a linhagem S-34, que possuem resistência monogênica às raças 1 e 2 e à raça 1 , respectivamente. No ensaio II comparou_se a patogenicidade entre o isolado $T-18-1$ e a raça 2 do patógeno. Neste ensaio foram incluídas 6 progênies de CAST-M-Wd, considerando-se o compurtamento destas no ensaio I. Usou-se, também, como diferenciais, a variedade Walter e a linhagem $\mathrm{S}-34$.

Os resultados obtidos permitiram tirar as seguintes conclusões: 1) 0 isolado T-18-1 pertence à raça 2 de Fusarium oxysporum 1 . sp. lycopersici; 2) a linhagem de tomateiro CAST-M-Wd, usada como diferencial na determinação da raça 3 do patógeno, năo possui re sistência monogênica e sim. resistência poligênica a raça 2; 3) o gene, I-2 encontrado na variedade Walter, mostra-se eficiente no controle da raç 2 (isolado T-18-1) assinalada no Brasll.

\section{INTRODUÇAO}

A "Murcha de Fusarium" causada por Fusarium oxysporum f. sp. lycopersici (Sacc) SNYDER \& HANS em tomateiro foi descrita, pela pri-

* Entregue para publicação em 19/12/1974.

Parte da tese apresentada pelo primeiro autor a Escola Superior de Agricultura sLuiz de Queiroz» para obtençăo do título de Mestre.

* Auxiliar de Ensino do Departamento de Fitossanidade da Faculdade de Agronomia «miseu Maciel, Pelotas. RS.

*** Ph. D., Professor Adjunto do Departamento de Fitopatologia da Escola Superior de Agricultura «luiz de Queiroz», Piracicaba, S. P. 
meira vez, em 1895 por MASSEE, fitopatologista inglês. Atualmente, sua distribuição é mundial, causando problemas de ordem econômica em quase todas as áreas onde o tomateiro é cultivado (23).

No Brasil, esta doença foi constatada primeiramente por ARRUDA (2), em 1939, no Estado de São Paulo. Posteriormente, outros pesquisadores $(8,17,21)$ a constataram praticamente em todo o Estado. Sua importância é tal que, em certas zonas produtoras daquele Estado, o cultivo do tomateiro está em fase de decadência face a infestação do solo por este patógeno (21).

Por causa da rápida reinfestação do solo, após tratamento químico, e da dificuldade de destruir completamente o fungo, a desifestação do solo permite somente um controle parcial do patógeno. Assim, a mais efetiva e barata medida de controle da doença é através do uso de variedades resistentes (20).

Até o ano de 1940, o tipo mais eficiente de resistência encontrada era aquela governada por vários genes. Este tipo de resistência permite que as plantas produzam normalmente quando as condições para a ocorrência da doença não são muito favoráveis. Porém, se estas forem favoráveis, as plantas "resistentes" mostram-se severamente afetadas (16).

A partir daquela data, passou-se a utilizar a resistência conferida pelo gene I de L. pimpinellifolium Mill. (introdução 160). Este gene confere praticamente, imunidade mesmo que ocorram condições ótimas para o desenvolvimento da doença (3).

Todo o trabalho de criação de variedades resistentes deve levar em consideração tanto a variabilidade do hospedeiro como a do agente causal, bem como sua distribuição.

EDGERTON (9), WHITE (26), HAYMAKER (11), WELMAN \& BLAISDEL (25), foram os primeiros pesquisadores a constatar a variabilidade de Fusarium oxysporum f. sp. Iycopersici, atribuída por BUXTON (4) à ocorrência de fenômenos de heterocariose e reprodução parassexual.

A constatação por ALEXANDER \& TUCKER (1), de uma nova raça do patógeno capaz de vencer a resistência conferida pelo gene I e sua ocorrência em diversos estados americanos $(1,10,13,15,18)$ e em alguns países, $(14,21,23)$ fez com que as pesquisas de fontes de resistência à nova raça fossem intensificadas.

STALL \& WALTER (19), em 1965, trabalhando com PI 126915, um híbrido entre L. esculentum e L. pimpinellifolium, selecionaram a linhagem PI 126915-1-8-1, homozigota para resistência às duas raças até então constatadas. CIRULLI \& ALEXANDER (5), apresentaram evidências de que a resistência a cada raça é determinada por diferentes genes e sugeriram

4 Informação pessoal fornecida ao Dr. Ferdinando Galli. 
o símbolo I-2 para o gene que governa a resistência à raça 2 , sendo que o grau de resistência conferido por este gene é semelhante àquele determinado pelo gene I (19).

A primeira variedade comercial com resistência às raças 1 e 2 , foi criada em 1969, no Agricultural Research and Education, Center Bradenton, Flórida, e recebeu o nome de Walter (20). Essa mesma instituição lançou, a variedade Florida $\mathrm{MH}-1$, que possui o memo tipo de resistência da variedade Walter (7).

TOKESHI (21), em 1966, no Estado de São Paulo, estudando a variabilidade do patógeno, descreveu um dos isolados T-18-1-, como pertencente à raça. 2. Prosseguindo no estudo do isolado TOKESHI et ali (22) verificaram que este causava mais de $50 \%$ de índice da doença em plantas da linhagem CAST-M-Wd que, segundo STALL 4 , possui gene de resistência às raças 1 e 2, na forma homozigota. Face ao observado, concluíram que 0 isolado em questão pertencia à raça 3 de Fusarium oxysporum f. sp. Iycopersici. Assim, a ocorrência, no Estado de São Paulo, de uma nova raça fisiológica do patógeno deverá ser considerada em trabalhos de melhoramento do tomateiro visando resistência à "Murcha de Fusarium".

Com o fito de fornecer informações básicas para o desenvolvimento de variedades resistentes, a presente investigação propôs-se, face as evidências acumuladas, determinar: 1) a que raça fisiológica pertence 0 isolado T-18-1; 2) qual o tipo de resistência que apresenta a linhagem CAST-M-Wd, usada como diferencial na determinação da raça 3.

\section{MATERIAL E MÉTODOS}

Foram utilizados nesse trabalho, a variedade Walter resistente às raças 1 e 2 de Fusarium; progênies obtidas por autofecundação de plantas da linhagem CAST-M-Wd que, segundo STALL, possui gene de resistência às raças 1 e 2 na forma homozigota; a linhagem S-34, homozigota para resistência à raça 1 e a variedade Santa Cruz Gigante Piedade, suscetível a todas às raças do patógeno.

Os isolados de Fusarium utilizados foram, respectivamente, a raça 2, obtida no Agricultural Research and Education, Center Bradenton, Florida e o isolado T-18-1, descrito por TOKESHI et alii (22) como pertencente à raça 3 , cedido pelo referido autor.

Para obtenção do inóculo usou-se a seguinte técnica: placas de Petri, contendo meio de batata-dextrose-agar (BDA) foram plaqueadas com Fusarium e incubadas por 5 a 7 dias à temperatura de $28^{\circ} \mathrm{C}$. Discos com 0,5 $\mathrm{cm}$ de diâmetro foram removidos das colônias e, cada disco, transferido para o frasco de Erlenmeyer de $250 \mathrm{ml}$.. contendo meio de cultura líquido com a seguinte constituição: caldo de $200 \mathrm{~g}$. de batata, $5 \mathrm{~g}$. de dextrose e água para completar $1000 \mathrm{ml}$. Após a transferência, os frascos foram mantidos no agitador à temperatura ambiente por 3 dias. 
Adotou-se, para a inoculação, a técnica recomendada por WELMAN (24) na qual as mudas, com aproximadamente 15 dias de idade, eram arrancadas com auxílio de espátula, suas raízes, lavadas em água corrente, mergulhadas no inóculo e imediatamente plantadas. Usaram-se $50 \mathrm{ml}$. do ìnóculo para cada variedade, linhagem ou progênie testada. Após as inoculações, as plantas ficaram protegidas por 3 dias da incidência direta do sol, a fim de se recuperarem do choque de transplante.

A avaliação dos sintomas causados por Fusarium, foi realizada, nos 2 ensaios, 30 dias após a inoculação, segundo critério de CIRULLI \& ALEXANDER (5), com ligeira modificação quanto ao valor das notas. As plantas foram selecionadas logo acima da linha do solo e classificadas segundo o critério apresentado no Quadro 1. Plantas às quais se atribuiram notas 2 e 3 foram classificadas como doentes; aquelas com nota 1, como sadias $(12,18,27)$. Sintomas que suscitassem dúvida, como clareamento de nervuras, não foram considerados.

QUADRO 1 - Critério de avaliação dos sintomas

Nota Sintolmas apresentados pelias plantas

1 Plantas sem sintomas externos e sem descoloração no caule

2 Plantas com ou sem leves sintomas externos mas com leve descoloração vascular

3 Plantas mortas e/ou plantas apresentando severos sintomas externos e extensiva descoloração vascular

1. Ensaio I. Reação das progênies de CAST-M-Wd ao isolado T-18-1 de Fusarium

Com a finalidade de verificar se alguma progênie segregava na proporção de 3 plantas resistentes para 1 suscetível, inocularam-se, com o isolado T-18-1, 27 progênies de CAST-M-Wd e as diferenciais Walter e S-34. A variedade Santa Cruz Gigante Piedade foi incluída no ensaio, sem inoculação, com a finalidade de detectar possíveis contaminantes patogênicos no solo.

A concentração usada no inóculo foi de $3.10^{7}$ esporos $/ \mathrm{ml}$., sendo que a temperatura do ar variou de 28 a $35^{\circ} \mathrm{C}$. e a do solo, de 24 a $28^{\circ} \mathrm{C}$.

0 delineamento estatístico foi de blocos ao acaso com 8 tratamentos e 5 repetições. Cada parcela era constituída por 8 plantas em vaso de alumínio contendo solo autoclavado.

2. Ensaio II - Comparação de patogenicidade entre o isolado T-18-1 e raça 2 de Fusarium

As progênies 1, 17, 4, 6, 13 e 28 de CAST-M-Wd entraram nesse ensaio, 
tendo-se por base o seu comportamento no ensaio $\mathrm{I}$ - as duas primeiras por apresentarem índices mais altos de doença, as progênies 4 e 6 por apresentarem índices intermediários e as duas últimas por mostrarem índices mais baixos. Juntamente com as 6 progênies de CAST-M-Wd foram incluídas a variedade Walter - resistente às raças 1 e 2 - e a linhagem S-34 - resistente à raça 1.Avariedade Santa Cruz Gigante Piedade foi incluída com a mesma finalidade com que entrou no ensaio $\mathrm{I}$.

A concentração do inóculo foi de $2.10^{7}$ esporos $/ \mathrm{ml}$. e a temperatura do ar variou de 28 a $40^{\circ} \mathrm{C}$., enquanto que a do solo de 24 a $35^{\circ} \mathrm{C}$.

0 delineamento estatístico foi de blocos ao acaso com 8 tratamentos e 4 repetições. Cada parcela era constituída por 5 plantas em vaso de alumínio contendo solo autoclavado.

\section{RESULTADOS}

1. Ensaio I - Reação das progênies de CAST-M-Wd ao isolado T18-1 de Fusarium

Os dados expressos em número de plantas sadias e doentes são apresentados no Quadro 2.

Os números mostraram, de uma maneira clara, que nenhuma progênie CASt-M-Wd segregou na proporção esperada. A progênie mais resistente apresentou $69,23 \%$ de plantas doentes e a mais suscetível 92,11\%, sendo que destas, $15,78 \%$ apresentaram-se severamente doentes. As 2 plantas da variedade Walter - que possui o gene I-2 - classificadas como doentes, apresentaram, apenas, leve descoloração vascular sem outros sintomas externos visíveis. Dentre 30 plantas da linhagem S-34, 27 mostraram-se severamente doentes, e as restantes, com leves sintomas externos e descoloração vascular.

0 númro desuniforme de plantas por variedade ${ }^{5}$, deve-se à morte de algumas, em consequência do transplante ou "damping-off" provocado pelo próprio Fusiarium.

A reação dessas plantas ao isolado T-18-1, expressa em médias de notas por parcela - dados transformados para $\sqrt{x+0,5}$ - é apresentada no Quadro 3.

5 variedade $=$ progênies, variedade e linhagem 
QUADRO 2 - Reação de 27 progênies de CAST-M-Wd, da variedade Walter e da linhagem S-34 ao isolado T-18-1 de Fusarium, expressa em número de plantas sadias, doentes, e em $\%$ de plantas doentes.

\begin{tabular}{|c|c|c|c|c|}
\hline Variedades & Sadias & Doentes & Total & $\%$ de plantas doentes \\
\hline 1 & 4 & 32 & 36 & 88,89 \\
\hline 2 & 10 & 30 & 40 & 75,00 \\
\hline 3 & 8 & 30 & 38 & 78,95 \\
\hline 4 & 3 & 35 & 38 & 92,11 \\
\hline 5 & 7 & 32 & 39 & 82,05 \\
\hline 6 & 8 & 32 & 40 & 80,00 \\
\hline 7 & 7 & 29 & 36 & 80,56 \\
\hline 8 & 7 & 31 & 38 & 81,58 \\
\hline 9 & 6 & 32 & 38 & 84,21 \\
\hline 10 & 10 & 28 & 38 & 73,68 \\
\hline 11 & 5 & 34 & 39 & 87,18 \\
\hline 12 & 8 & 31 & 39 & 79,49 \\
\hline 13 & 8 & 31 & 39 & 79,49 \\
\hline 14 & 7 & 32 & 39 & 82,05 \\
\hline 16 & 6 & 33 & 39 & 84,62 \\
\hline 17 & 6 & 33 & 38 & 84,21 \\
\hline 18 & 6 & 29 & 35 & 83,33 \\
\hline 19 & 5 & 34 & 39 & 87,18 \\
\hline 20 & 4 & 34 & 38 & 89,47 \\
\hline 21 & 8 & 29 & 37 & 78,38 \\
\hline 22 & 4 & 36 & 39 & 89,74 \\
\hline 23 & 9 & 31 & 40 & 77,50 \\
\hline 24 & 4 & 33 & 37 & 89,19 \\
\hline 25 & 12 & 27 & 39 & 69,23 \\
\hline 26 & 5 & 30 & 35 & 85,71 \\
\hline 27 & 5 & 29 & 34 & 85,29 \\
\hline 28 & 8 & 31 & 39 & $79,49$. \\
\hline Walter & 35 & 2 & 37 & 5,71 \\
\hline S-34 & - & 30 & 30 & 100,00 \\
\hline
\end{tabular}


QUADRO 3. Reação de 27 progênies de CAST-M-Wd, de variedade Walter e da linhagem S-34 ao isolado T-18-1 de Fusarium, expressa em média de notas por parcela. Dados transformados para $\sqrt{x+0,5}$

\begin{tabular}{|c|c|c|c|c|c|c|}
\hline \multirow{2}{*}{ Variedades } & \multicolumn{5}{|c|}{ Repetições } & \multirow{2}{*}{$\frac{\text { Médias }}{\text { Médias * }}$} \\
\hline & $\mathrm{I}$ & III & III & IV & $\mathrm{V}$ & \\
\hline 1 & 1,68 & 1,70 & 1,62 & 1,67 & 1,66 & $1,67 \mathrm{a} \mathrm{b}$ \\
\hline 2 & 1,54 & 1,62 & 1,54 & 1,70 & 1,41 & $1,56 \quad b$ \\
\hline 3 & 1,62 & 1,66 & 1,46 & 1,54 & 1,63 & $1,58 \mathrm{a} \mathrm{b}$ \\
\hline 3 & 1,62 & 1,66 & 1,46 & 1,54 & 1,63 & $1,58 \mathrm{a} \mathrm{b}$ \\
\hline 4 & 1,70 & 1,62 & 1,62 & 1,46 & 1,62 & 1,69 a b \\
\hline 5 & 1,58 & 1,62 & 1,62 & 1,58 & $-1,54$ & $1,59 \mathrm{a} \mathrm{b}$ \\
\hline 6 & 1,62 & 1,70 & 1,62 & 1,54 & 1,62 & $1,62 \mathrm{a} \mathrm{b}$ \\
\hline 7 & 1,70 & 1,75 & 1,58 & 1,58 & 1,38 & $1,60 \mathrm{ab}$ \\
\hline 8 & 1,58 & 1,66 & 1,50 & 1,58 & 1,73 & $1,61 \mathrm{a} \mathrm{b}$ \\
\hline 9 & 1,41 & 1,70 & 1,62 & 1,53 & 1,66 & $1,58 \mathrm{a} \mathrm{b}$ \\
\hline 10 & 1,53 & 1,58 & 1,70 & 1,50 & 1,58 & $1,58 \mathrm{a} \mathrm{b}$ \\
\hline 11 & 1,58 & 1,46 & 1,62 & 1,73 & 1,73 & $1,62 \mathrm{a} \mathrm{b}$ \\
\hline 12 & 1,70 & 1,66 & 1,58 & 1,73 & 1,58 & $1,65 \mathrm{a} \mathrm{b}$ \\
\hline 13 & 1,73 & 1,62 & 1,54 & 1,54 & 1,50 & $1,59 \mathrm{a} \mathrm{b}$ \\
\hline 14 & 1,70 & 1,50 & 1,67 & 1,66 & 1,54 & $1,61 \mathrm{a} \mathrm{b}$ \\
\hline 16 & 1,62 & 1,62 & 1,44 & 1,66 & 1,73 & $1,61 \mathrm{ab}$ \\
\hline 17 & 1,58 & 1,62 & 1,70 & 1,54 & 1,73 & $1,63 \mathrm{a} \mathrm{b}$ \\
\hline 18 & 1,71 & 1,47 & 1,70 & 1,58 & 1,71 & $1,63 \mathrm{a} \mathrm{b}$ \\
\hline 19 & 1,66 & 1,54 & 1,66 & 1,66 & 1,67 & $1,64 \mathrm{a} \mathrm{b}$ \\
\hline 20 & 1,67 & 1,62 & 1,73 & 1,58 & 1,77 & $1,67 \mathrm{a} b$ \\
\hline 21 & 1,41 & 1,66 & 1,58 & 1,58 & 1,73 & $1,59 \mathrm{a} \mathrm{b}$ \\
\hline 22 & 1,58 & 1,66 & 1,67 & 1,62 & 1,77 & $1,66 \mathrm{a} \mathrm{b}$ \\
\hline 23 & 1,58 & 1,58 & 1,41 & 1,66 & 1,70 & $1,59 \mathrm{a} \mathrm{b}$ \\
\hline 24 & 1,62 & 1,62 & 1,67 & 1,67 & 1,66 & $1,65 \mathrm{a} \mathrm{b}$ \\
\hline 25 & 1,54 & 1,62 & 1,50 & 1,49 & 1,58 & $1,55 \mathrm{a} \mathrm{b}$ \\
\hline 26 & 1,73 & 1,67 & 1,58 & 1,70 & 1,66 & $1,67 \mathrm{a} \mathrm{b}$ \\
\hline 27 & 1,50 & 1,62 & 1,62 & 1,63 & 1,73 & 1,62 a b \\
\hline 28 & 1,62 & 1,50 & 1,62 & 1,54 & 1,62 & $1,58 \mathrm{a} \mathrm{b}$ \\
\hline Walter & 1,22 & 1,22 & 1,22 & 1,22 & 1,34 & $1,24 \quad \mathrm{c}$ \\
\hline S-34 & 1,79 & 1,82 & 1,79 & 1,82 & 1,82 & $1,81 \mathrm{a}$ \\
\hline
\end{tabular}


Nota-se que com exceção das progênies 2 e 25 as demais não diferiram da linhagem S-34, que não possui o gene I-2. Entretanto, as progênies não diferiram entre si. A variedade Walter diferiu de todas as progênies de CAST-M-Wd e da linhagem S-34.

A variedade Santa Cruz Gigante Piedade não detectou a presença de contaminantes patógenicos no solo.

2. Ensaio II - Comparação de patogenicidade entre o isolado T-18-1 e a raça 2 de Fusarium

$\mathrm{O}_{\mathrm{S}}$ resultados expressos em médias de notas por parcela transformados para $\sqrt{x+0,5}$, são apresentados no Quadro 4. Estatísticamente, distingue-se 3 grupos: um formado pela linhagem S-34, outro pelas 6 progênies de CAST-M-Wd e o último pela variedade Walter, conforme pode ser visto no Quadro 5.

Quadro 4. Comparação de patogenicidade entre o isolado T-18-1 e a raça 2 de Fusarium Dados transformados para $\sqrt{\times+0,5}$

\begin{tabular}{|c|c|c|c|c|c|c|}
\hline \multirow{2}{*}{ Variedades } & \multirow{2}{*}{ Isolados } & \multicolumn{5}{|c|}{ Repetições } \\
\hline & & $I$ & II & III & IV & Médias * \\
\hline \multirow[t]{2}{*}{1} & $T-18-1$ & 1,45 & 1,52 & 1,45 & 1,45 & 1,47 \\
\hline & Raça 2 & 1,52 & 1,58 & 1,58 & 1,45 & 1,53 \\
\hline \multirow[t]{2}{*}{6} & T-18-1 & 1,52 & 1,52 & 1,45 & 1,45 & 1,49 \\
\hline & Raça 2 & 1,58 & 1,52 & 1,58 & 1,52 & 1,55 \\
\hline \multirow[t]{2}{*}{17} & T-18-1 & 1,52 & 1,52 & 1,45 & 1,52 & 1,50 \\
\hline & Raça 2 & 1,45 & 1,38 & 1,58 & 1,52 & 1,48 \\
\hline \multirow[t]{2}{*}{4} & $T-18-1$ & 1,45 & 1,52 & 1,64 & 1,52 & 1,53 \\
\hline & Raça 2 & 1,52 & 1,52 & 1,58 & 1,58 & 1,55 \\
\hline \multirow[t]{2}{*}{13} & $T-18-1$ & 1,45 & 1,52 & 1,70 & 1,45 & 1,53 \\
\hline & Raça 2 & 1,38 & 1,64 & 1,58 & 1,52 & 1,53 \\
\hline \multirow[t]{2}{*}{28} & $T-18-1$ & 1,30 & 1,64 & 1,58 & 1,45 & 1,49 \\
\hline & Raça 2 & 1,30 & 1,52 & 1,64 & 1,52 & 1,50 \\
\hline \multirow[t]{2}{*}{ Walter } & $\mathrm{T}-18-1$ & 1,22 & 1,30 & 1,30 & 1,30 & 1,28 \\
\hline & Raça 2 & 1,22 & 1,38 & 1,22 & 1,22 & 1,26 \\
\hline \multirow[t]{2}{*}{ S-34 } & T-18-1 & 1,70 & 1,87 & 1,82 & 1,76 & 1,79 \\
\hline & Raça 2 & 1,32 & 1,87 & 1,87 & 1,32 & 1,55 \\
\hline
\end{tabular}

* As comparações entre médias são apresentadas no quadro 5. 
Quadro 5. Comparações entre médias de variedades inoculadas com o isolado T-18-1 e raça 2 de Fusarium. Ensaio II

\begin{tabular}{|c|c|c|}
\hline Variedades & Médis & as * \\
\hline 1 & 1,50 & b \\
\hline 6 & 1,52 & b \\
\hline 17 & 1,49 & b \\
\hline 4 & 1,54 & b \\
\hline 13 & 1,53 & b \\
\hline 28 & 1,49 & b \\
\hline Walter & 1,27 & c \\
\hline S-34 & 1,82 & a \\
\hline
\end{tabular}

* = médias com letras iguais não diferem entre si pelo teste de Tukey a 1\%

Nesse ensaio, também, não foi detectada a presença de contaminantes patogênicos no solo.

\section{DISCUSSÃO}

Os dados expostos no Quadro 2, mostraram de uma maneira bem clara, que nenhuma progênie segregou na proporção esperada - 3 resistentes: 1 suscetível. Entretanto, os resultados do ensaio I mostraram que, com exceção das progênies 2 e 25, as demais não diferem da linhagem S-34 que não possui o gene I-2. Porém, toda as progênies de CAST-M-Wd diferem da variedade Walter que carrega o gene I-2.

Apesar de, no ensaio I, 25 progênies de CAST-M-Wd apresentarem um comportamento, estatisticamente, semelhante ao da linhagem S-34, nota-se que nesta última a percentagem de plantas doentes foi de $100 \%$, sendo que, destas, 90,00\% mostravam-se severamente doentes. A progênie de CAST-M-Wd que apresentou maior percentagem de plantas doentes o fez com 92,11\%, destas, apenas $15,78 \%$ foram classificadas como severamente doentes. Isto indica que as progênies de CAST-M-Wd possuem maior resistência que a linhagem S-34, todavia, esta resistência parece ser condicionada por outros genes que não o I-2 encontrado na variedade Walter. 0 exame do «pedigree» da linhagem CAST-M-Wd mostra que na sua seleção, os primeiros cruzamentos envolveram variedades com resistência poligênica à Fusarium, sendo posteriormente incorporado o gene I-2 de L. pimpinellifolium - PI 126915-1 (20).

CRILL et alii (6) salientam que variedades com resistência poligênica podem se comportar como suscetíveis quando a concentração do inóculo for muito elevada. Situação semelhante ocorreu no ensaio I, onde, com uma concentração de $3.10^{7}$ esporos/ml., 25 de 27 progênies de CAST-M-Wd com- 
portaram-se como a linhagem S-34, altamente suscetível. Já no ensaio II, com uma concentração de $2.10^{7}$ esporos $/ \mathrm{ml}$., foi possível distinguir as progênies de CAST-M-Wd da linhagem S-34. Porém, nos 2 ensaios, nenhuma progênie de CAST-M-Wd comportou-se como a variedade Walter.

Os resultados dos ensaios I e II indicam que, provavelmente, a resistência das progênies de CAST-M-Wd à raça 2 de Fusarium é condicionada por vários genes e não pelo gene I-2.

Considerando o exposto e, como as progênies de CAST-M-Wd não diferiram entre si, nos 2 ensaios, a hipótese de falta de pureza genética quanto ao gene I-2 não se confirmou. Assim, as sementes da linhagem CAST-MWd, utilizadas por TOKESHI et alii (22), careciam do gene I-2, possuindo, entretanto, resistência horizontal à raça 2 de Fusarium, resistência esta que é quebrada quando a concentração de inóculo for muito elevada.

A ausência do gene I-2 nas sementes da linhagem CAST-M-Wd, usada por TOKESHI et alii (22), possivelmente tenha ocorrido por uma falha no método de seleção. Assim, planta ou plantas carentes desse gene, mas com resistência horizontal, foram selecionadas. Mesmo em programas de melhoramento, onde variedades testadas são rotineiramente conduzidas, é possível ocorrer a perda de genes de resistência, principalmente se estes estão associados com resistência horizontal (7).

Atribui-se a uma falha, durante a avaliação dos sintomas, o comportamento das progênies 2 e 25 que se mostraram, estatisticamente, mais resistentes que a linhagem S-34, no ensaio $I$.

Não obstante o gene I-2 conferir uma quase imunidade (19), algumas plantas da variedade Walter mostraram-se doentes, tanto no ensaio I como no II. Estes resultados estão em desacordo com os obtidos por CRILL et alii (6), segundo os quais, de 75 plantas, de variedade resistente, testadas com a raça 2 de Fusarium - com uma concentração de $10,5.10^{6}$ esporos por ml. - nenhuma mostrou sintomas da doença. Parece que a maior concentração de inóculo utilizada neste trabalho foi a responsável pelos resultados obtidos .

\section{CONCLUSOESS}

Dos resultados obtidos no presente trabalho, pode-se concluir que:

\subsection{0 isolado T-18-1 pertence à raça 2 de Fusarium.}

5.2. A linhagem de tomateiro CAST-M-Wd não possui o gene I-2 e sim, resistência horizontal à raça 2 de Fusarium.

5.3. 0 gene I-2, encontrado na variedade Walter, mostra-se eficiente no controle da raça 2 (isolado T-18-1) de Fusarium assinalada no Brasil. 


\section{SUMMARY}

\section{REVIEW OF CLASSIFICATION OF RACE 3 OF FUSARIUM OXYSPO. RUM F. SP. LYCOPERSICI}

The authors endeavored to determine: 1) to which physiologic race isolate T-18-1 belongs, previsously identified as race 3 of Fusarium oxysporum f. sp. Iycopersici; 2) what type of resistance is present in line CAST$\mathrm{M}-\mathrm{Wd}$, used as a differential in determination of race 3.

To attain the objectives desired, 2 experiments were designed in a greenhouse under partial temperature control. In the first experiment the pathogenicity of isolate T-18-1 was determined for 27 progenies of CAST-M-Wd. Variety Walter and line S-34 were used as diferentials since they possess monogenic resistance to races 1 and 2 race 1 , respectively. In the second experiment, the pathogenicity of isolate T-18-1 was compared with races 2 of the pathogen. Six progenies of CAST-M-Wd were selected to be used on the basis of results in the first experiment. Variety Walter and line S-34 were used algo.

On the basis of the results the following conclusions are drawn: 1) the isolate T-18-1 belongs to race 2 of Fusarium oxysporum f. sp. Iycopersici; 2) the tomato line CAST-M-Wd, used previsously as a differential in the identification of race 3 , does not possess monogenic resistance but has polygenic resistance to race $3 ; 3$ ) gene I-2 in variety Walter demonstrates sufficient resistance for the control of race 2 (isolate T-18-1) as reported in Brazil.

\section{LITERATURA CITADA}

ALEXANDER, L. J. \& TUKER, C. M. Physiologic specialization in the tomato wilt fungus Fusarium oxysporum f. Iycopersici. J. agric. Res. Washington, 70(9): 303-313, 1945.

ARRUDA, S. C. Murcha de Fusarium do tomateiro. Biológico, São Paulo, y (7) : 199-200, 1941.

BOHN, G. W. \& TUCKER, C. M. Immunity to Fusarium wilt in the tomato. Science New York, 89 (2322) : 603-604, 1939.

BUXTON, E. W. Mechanism of variation in Fusarium oxysporum in relation to host parasite interaction. In: HOLTON, C. S. et alii, ed. Plant Pathology: problems and progress - 1908-1958. Madison, University of Wisconsin, 1959. p. 183-191.

CIRULLI, M. \& ALEXANDER, L. J. A comparison of pathogenic isollates of Fusarium oxysporum f. Iycopersici and different sources of resistance in tomato. Phytopathology Lancaster, 56 : 1301-1304. 1966.

CRILL, P. et alii. Controlng Fusarium wilt of tomato with resistant varieties. Plant Dis. Reptr. Washington, 56 (8) : 695-699, 1972.

CRILL, P. et alii. Controlling Fusarium wilt of tomato with host resistance. Bradenton, University of Florida, 1973. $10 \mathrm{p}$.

CRUZ, B. P. B. Principais doenças fúngicas do tomateiro em São Paulo. Biológico, São Paulo, 29 (10) : 201-208, 1963. 
EDGERTON, C. W. A study of wilt resistence in the seed-bed. Phytopathology, 8 : 5-14, 1918.

GERDEMANN, J. W. \& FINLEY, A. M. The pathogenicity of races 1 and 2 of Fusarium oxysporum f. lycopersici. Phytopathology, 41 : 238-244, 1951.

HAYMAKER, H. H. Pathogenicity of two strains of tomato wilt fungus, Fusarium lycopersici Sacc. J. agric. Res., Washington, 36 (8) : 675-695, 1928.

HENDERSON, W. R. \& WINSTEAD, N. N. Reaction of tomaito varieties and breeding lines to Fusarium oxysporum f. lycopersici race 1. Plant Dis. Rcptr., Washington, 45 (4) : 272-273, 1961.

JONES, J. P. \& LTTTRELL, R. H. Another appearance in Florida of a wilt Fusarium pathogenic to race 1 resistant tomato varieties. Plant. Dis. Reptr., Washington, 49 (6) : 536-537, 1965.

MATSUOKA, K. Nova raça fisiológica de Fusarium oxysporum f. lycopersici em Minas Gerais. Revista da Sociedade Brasileira de Fitopatologia, Campinas, $3: 80,1969$.

MILIER, R. E. \& KANANEN, D. L. Occurrence of Fusarium oxysporum f. sp. lycopersici race 2 causing wilt of tomato in New Jersey. Plant. Dis. Reptr., Washington, $52(7): 533-554,1968$.

SHERBAKOFF, C. D. Breeding for resistance to Fusarium and Verticillium wilts. Bot. Rev., 15 : 377-422, 1949.

SILVEIRA, A. P. da et alii. Experimentos de resistência varietal às murchas de Fusarium e Verticillium do tomaiteiro. Archos. Inst. Biol., São Paulo, 33 (3) : 73-79, 1966.

STTALL, R. E. Development of Fusarium wilt on resistant varieties of tomato caused by a strain different from race 1 isolates of Fusarium oxysporum f. lycopersici. Plant. Dis. Reptr., Washington, 48 (1) : 12-15, 1961.

STALL, R. E. \& WALTER, J. N. Selection and inheritance of resistence in tomato to isolates of races 1 and 2 of Fusarium wilt organism. Phytopathology, 55 : 1213-1215, 1965 .

STROBEL, J. W. et alii. Walter a determinate tomato resistant to races 1 and 2 of the FUSARIUM wilt pathogen. Bradenton, University of Florida, 1969, $9 \mathrm{p}$. (Circular S-202).

TOKESHI, H. Murcha de Fusarium em tomateiro: estudo da variabilidade do patógeno e hospedeiro. Piracicaba, Escola Sruperior de Agricultura «Luiz de Queiroz», 1966. 64 p. (itese de Livre Docência).

TOKESHI, $\mathrm{H}$. et alii. Nova raça de Fusarium do tomateiro em São Paulo. Anais Esc. Sup. Agric. «Luiz de Queiroz», Piracicaba, 23 : 217-227, 1966.

WALKER, J. C. Fusarium wilt of tomato. St. Paul, American Phytopathological Society, 1971. 5 p. (Monograph n.9 6).

WELLMAN, F. L. A technique for studying host resistance and pathogenicity in tomato Fusarium wilt. Phytopatholoy, 29 : 945-955, 1939.

WELLMAN, F. L. \& BLAISDELL, D. J. Pathogenic and cultural variation among single-spore isolates from strains of the tomato wilt Fusarium. Phytopathology, 31 : 103-120, 1941.

WHITE, R. P. Studies on tomato wilt caused by Fusarium lycopersici Sacc. J. agric. Res., Washington, 34 : 197-239, 1927.

WINSTEAD, N. N. \& HENDERSON, W. R. Tomato varieties or susceptible to Fusarium oxysporum f. lycopersici, race 1. Plant. Dis. Reptr., Washington, 48(9: 690-691, 1964. 